\title{
Factors Affecting Decision Making among Nurse Managers and Its Relation to Decision Making Styles
}

\author{
Hind Abdullah Mohamed ${ }^{1}$, Huda Reda Elrais ${ }^{2}$, \\ ${ }^{1}$ lecturer of Nursing Administration department, Faculty of Nursing, Port Said \\ University, Egypt, ${ }^{2}$ Nursing Administration department, Faculty of Nursing, Port \\ Said University, Egypt
}

\begin{abstract}
Background: Decision making is the heart of all administrative and managerial functions. Managers make many decisions as a part of their daily work by different styles and those decisions and styles are affected by many factors. Aim: This study aimed to assess the factors affecting decision-making among nurse managers and its relation to decision-making styles. Material and methods: A descriptive correlation research design was utilized with a sample of 85 nurse managers who were working in Port Said hospitals which affiliated to Ministry of Health. Data was collected from November 2014 to January 2015.Tools of data collection: A personal and job characteristics of the participants, factors affecting decision making questionnaire and general decision-making style inventory (GDMS) were used. Results: The study findings revealed that less than half $(42.4 \%)$ of nurse managers were influenced by the factors affecting decision making. The highest mean score was for process factors (79.4 \pm 13.0$)$, meanwhile the lowest mean score was for individual factors $(72.9 \pm 13.7)$. Additionally, the highest mean score was for avoidant style (18.2 \pm 3.7$)$, while the lowest mean scores was for rational style (10.5 \pm 2.3$)$. Conclusion: There was a statistically significant correlation between factors affecting decision making and all general decision-making styles except the intuitive style. So the findings pointed to create nurse managers abilities related to decision making through educational programs. Also, further researches are suggested.
\end{abstract}

Keywords: Decision-making styles, factors affecting decision making, nurse managers. 


\section{INTRODUCTION}

Nowadays, there is an expanded requirement for expert nurses to be self-sufficient, fit for free thought and ready to decide on their actions. The nursing practice calls for the cognition capacities that incorporate making decisions and solve problems (Yuan, Kunaviktikul, Klunkin, \&Williams, 2009). Nursing supervisors and managers are facing consistent alterations in the environment of health care and this usually calls for customized choices accessible from previous experience to find solutions or noncustomized choices that devise new techniques to deal with the circumstances of the specific in-hand issue (Schermerhorn, 2005).

Basic leadership is a procedure of settling on a decision among contending choices and the usage of the picked contrasting option to accomplish individual and authoritative goals (Guo, 2004). The association between an issue that should be worked out and an administrator who wishes to fathom it inside a particular situation is referred to as the process of decision making (Dumler, 2007). Leaders decide on numerous choices as a piece of their day by day work, and a number of their choices have noteworthy outcomes for execution, it encourages the whole administration operation, a nonstop administrative capacity, and basic to confront new issues and difficulties (Greenberg, 2011; Lussier, 2014) .The element that usually judge whether administrators and supervisors are successful or not is how good the actions and decisions they take are (Marquis \& Huston, 2014).

Pinpointing the elements that may influence decisions, can enhance the process of making decisions through proposing new options or uncovering concealed imperatives that should be tended to before the ideal decision making is conceivable ( Charise, et al., 2010). There are various elements that influence making decisions and help nurse directors take decisions very rapidly. Such elements are the authoritative and administrative culture, the best administrative support, the satisfactory staffing and even the time requirements (Effken, Verran, Logue, \& Hsu, 2010).

Directors are supposed to make a continuous assessment of situations and decide on actions with respect to what they - the situations - produce, how they develop and the available resources. The way in which a director settles on choices is imperative in seeing how successful he or she will be in a given circumstance. It has been claimed that the style of decision making is closely related to the main features of a director's 
conviction framework that are used in the process of taking a decision, usually unwittingly it is the inclinations that form a style that pinpoints the sorts of data and experiences that are saved and utilized afterwards in making decisions (Fox \& Spence, 1999). Different conditions demand diverse styles and characteristics that directors need to take a decision (Beschloss, 2007). The style of decision-making is the educated continual reaction design shown by a person when gone up against with an issue that needs taking a decision (Scott \& Bruce, 1995). In addition, the 'style of decision-making' referred to as the word we use to portray how a person gathers, sees and processes data all through their profession decision-making stations, that is, the way of taking profession decisions and the way the participate simultaneously (Gati , Landman, Dowidovitch, Asulinperetz,\& Gadassi, 2010).

The 'styles of making decisions' are diverse. Scott and Bruce (1995) have classified the most well-known five as; spontaneous ( aptness to take quick decisions ), intuitive ( dependence on instinct not logic ), avoidant ( an inclination to evade and bypass the act of deciding ), dependent ( counsel demanding and depending on others ) and rational ( through collecting data and coherent assessment of the options ). Perhaps the medical attendant supervisor needs to adopt different styles to decide on an action.

Furthermore, their styles of 'decision-making' rely upon conditions such as time, expertise viewpoints, previous encounters, data and innovativeness (Yoder- Wise, 2014). I was observed that, the style of 'decision-making' could be utilized properly or improperly; the conditions of the issue ought to impose which style of 'decisionmaking' is best suitable (Yoder- Wise, 2014). Individuals with different cultural backgrounds don't really decide on their actions similarly. Time orientation frequently controls the style of 'decision-making' they apply (Lussier, 2014).

\section{Significance of the study}

It is widely agreed that the heart of management is the process of 'making decisions'. And everybody is expecting directors to do this (Basavanthappa, 2009). In addition, the achievement an organization makes relies - to a great extent - on the operations of taking decisions (Huber, 2014). Individuals are daily proposed with choices and decisions. Some part of cognitive psychology pays attention to explaining how individuals settle on their choices and decisions. Many hypotheses have been created to clarify the way people settle on their choices and decisions and what sort of 
elements impact their action of taking decisions at present or in the future (Dietrich, 2010) . Nursing directors confront with circumstances (chances or risks) that need to settle on choices and decisions in fulfilling their tasks. Thusly, they have to comprehend the elements influencing their action of taking a decision that may improve and enhance their choice or decision. The element that usually judge whether administrators and supervisors are successful or not is how good the actions and decisions they take are (Marquis\& Huston, 2014). Nobody tried to survey the connection between the variables influencing 'taking decision' among nursing directors and its connection to their style of 'making decision'. Therefore, this research is done to aid nursing directors comprehend these variables and seek the proper style of decision-making.

\section{AIM OF STUDY:}

This study aimed to assess the factors affecting decision-making among nurse managers and its relation to decision-making styles.

\section{Research questions}

RQ1: What are the factors affecting decision making among nurse managers?

RQ2: What are the decision-making styles among nurse managers?

RQ3: Is there a relationship between the factors affecting decision-making among nurse managers and their decision-making styles?

\section{SUBJECT AND METHODS:}

\section{Study design:}

A descriptive correlational research design was used for fulfilling the aim of the study.

\section{Setting:}

The study was conducted in the seven public hospitals which affiliated to Ministry of Health, in Port Said governorate as follows: Port Said general hospital, Port Foad general hospital, El-Nasr general hospital, El-Zhour general hospital, Port Said chest hospital, Port Said fevers hospital, and Port Said ophthalmology hospital.

\section{Subject:}


The target population of this study was all nurse managers who are working in the above mentioned settings and available at the time of data collection with total number (85) nurse managers. Nurse mangers who agree to participate and have at least one year of experience in their current job have been included in the study. They were classified as follows; Port Said general hospital(16), Port Foad general hospital(17), El-Nasr general hospital(13), El-Zhour general hospital(9), Port Said chest hospital(10), Port Said fevers hospital(9) and Port Said ophthalmology hospital(11).

Tools of data collection: Data of this study was collected by using two tools.

Tool (1): Factors Affecting Decision Making Questionnaire: it consists of two parts

\section{- Part (I): Personal and job characteristics data sheet}

This part was developed by the researcher and includes data related to the personal and job characteristics of the studied nurse managers such as the age, marital status, level of education, years of experiences, and previous attendance of training courses.

\section{- Part (II): Factors Affecting Decision Making Questionnaire}

This part was developed by Craig \& Smyth (2002) and translated into Arabic language. It aims to determine the factors that affect decision making among nurse managers. It consists of 71 statements classified into four types of factors affecting decision making, namely; structural factors (34 items), process factors (11 items), outcome factors( 3 items) and individual factors(23 items).

\section{Scoring system:}

The participant's response to each statement was measured on a three point Likert scale as follows; "yes", "sometimes", and "no". These were respectively scored 2, 1, and 0 . The scores of each category were summed up and the total was divided by the number of the items, giving a mean score for the domain. These scores were converted into a percentage score. The category of factors was considered to be influencing decision making if the percentage score was $60 \%$ or more, and not influencing if less than $60 \%$ (Soliman, 2010). 


\section{Tool (2): General Decision-Making Style Inventory (GDMS):}

It was developed by Scott \& Bruce (1995) and translated into Arabic language. It aims to assess decision-making styles of nurse managers. It consists of 25 items divided into five decisional styles, namely: rational (5 items), dependent (5 items), avoidant (5 items), intuitive (5 items), and spontaneous (5 items).

\section{Scoring system:}

The participant's responses to each statement were measured on a five point Likert scale as follows; "strongly disagree", "disagree, "neutral (neither agree nor disagree) ", "agree", and "strongly agree" these were respectively scored 1, 2, 3, 4, and 5. For each style of GDMS, the scores of the items were computed by adding the score on each of the 5 styles items, resulting in values from 5 to 25 . The score of each nurse manager was converted into a percentage score. If the percentage score was equal or more than $75 \%$, it was considered as high style level, if the percentage score was from $60 \%$ to less than $75 \%$, it was considered as moderate style level, and if the percentage score was less than60\%, it was considered as low style level (Scott \& Bruce, 1995).

\section{Validity and reliability of tool:}

The researchers translated the tools into Arabic. Then, a bilingual specialist translated this Arabic interpretation into English again. Finally, they compared the three versions. The tools' face and content validity were checked by a board of five specialists in the field and they gave no negative comments. The Cronbach's Alpha coefficient for the present questionnaire was 0.79 while Cronbach's Alpha reliability test of Factors Affecting Decision Making Questionnaire has been established before with alpha coefficient 0 . 81. Reliability of the General Decision-Making Style Inventory (GDMS) established before was 0.78 , while for the current questionnaire the Cronbach's alpha was 0.84 .

\section{Pilot study:}

Nine nurse managers - representing $10 \%$ of the 85 who were chosen randomly - have participated in a pilot study before starting the data collection to check the feasibility, applicability, how clear the tools are and to allocate the time needed to fill it. The nine participants in the pilot study were included in the study. 


\section{Ethical consideration:}

The medical and nursing directors of the hospitals studied to collect the necessary date have written their approval to participate in the study. After explaining the aim of the study and taking the verbal consent from every nurse manager for participation, some ethical issues were raised. Henceforth, anonymity was assured and maintained, no coercion or pressure was applied, and no risk or burden was imposed on participants. Confidentiality of the data gathered was assured and it was only used for the purpose of the study. Finally, they were all informed about their right to refuse participation or even withdrawal at any time.

\section{Field work:}

The data was collected two days a week for 3 months throughout the period from November 2014 to January 2015. It was done during the morning shift between 10:00 am to $12: 00 \mathrm{pm}$. The researcher was always there to answer any questions and clarify any ambiguities.

\section{Statistical analysis :}

The data was analyzed by the (SPSS) - the Statistical Package for Social Sciences software package version 20.0 - after being coded and computerized. Using mean and standard deviation for quantitative data, frequency \& percentage for qualitative data, Pearson correlation coefficient was used, statistical significance was considered at the 0.05 level.

\section{RESULTS:}

Table (1): shows personal and job characteristics of the nurse managers. As the table indicated, $35.3 \%$ of the nurse managers were in the age group $30<40$ years old, with the mean of $43.1 \pm 9.3$ years, $88.2 \%$ of them were married. $76.5 \%$ of them had a nursing diploma. As shown in the table, $37.6 \%$ of them had experience years ranged between 20 to less than 30 years. Also, the highest percentages $(76.5 \%)$ were attending training courses in management.

Table (2): describes the factors affecting decision making as perceived by the nurse managers. It is evident that less than half (42.4\%) of nurse managers reported that the factors affecting decision making are influencing their decisions. The highest mean 
score among the factors affecting decision making was for process factors (79.4 \pm 13.0$)$, followed by structural factors $(78.6 \pm 11.7)$, while the lowest mean score was found for the individual factors $(72.9 \pm 13.7)$.

Table (3): reveals the mean and standard deviation of the nurse managers' scores toward general decision-making styles. It is clear from the table that the highest mean score for avoidant style (18.2 \pm 3.7$)$, followed by spontaneous style (16.5 \pm 3.6$)$, while the lowest mean scores for rational style $(10.5 \pm 2.3)$.

Table (4): illustrates general decision-making styles levels as perceived by the nurse managers. The table showed that the high percent $(92.9 \%, 64.7 \%$, and $64.7 \%)$ of nurse managers had low (rational, intuitive and dependent decision-making styles respectively. While, less than two thirds of them had high avoidant style. Additionally, $42.4 \%$ of nurse mangers had moderate spontaneous style.

Table (5): points the correlation between general decision-making styles (GDMS) and factors affecting decision making among nurse managers. As the table indicated, that there was a statistically significant correlation between factors affecting decisionmaking and dependent, avoidant, and spontaneous decision-making styles. Additionally, rational style had statistically significant correlation with process factors. Meanwhile, no significant correlation was found between factors affecting decision-making and intuitive style. 
Table (1): Personal and job characteristics of the nurse managers in the public hospitals $(\mathrm{n}=85)$.

\begin{tabular}{|c|c|c|}
\hline \multirow{2}{*}{ Socio-demographic characteristics } & \multicolumn{2}{|c|}{ nurse managers $(n=85)$} \\
\hline & No. & $\%$ \\
\hline \multicolumn{3}{|l|}{ Age (years) } \\
\hline $20<30$ & 3 & 3.5 \\
\hline $30<40$ & 30 & 35.3 \\
\hline $40<50$ & 28 & 32.9 \\
\hline $50 \leq 60$ & 24 & 28.3 \\
\hline Range & \multicolumn{2}{|c|}{$22.0-59.0$} \\
\hline Mean \pm SD & \multicolumn{2}{|c|}{$43.1 \pm 9.3$} \\
\hline \multicolumn{3}{|l|}{ Marital Status } \\
\hline Single & 2 & 2.4 \\
\hline Married & 75 & 88.2 \\
\hline Divorced/widow & 8 & 9.4 \\
\hline \multicolumn{3}{|l|}{ Educational Qualifications } \\
\hline Nursing diploma & 65 & 76.5 \\
\hline Specialist diploma of nursing & 2 & 2.4 \\
\hline Technical institute & 3 & 3.5 \\
\hline Bachelor of nursing & 15 & 17.6 \\
\hline \multicolumn{3}{|l|}{ Duration of Nursing Experience (years) } \\
\hline Less than 10 & 8 & 9.4 \\
\hline $10<20$ & 22 & 25.9 \\
\hline $20<30$ & 32 & 37.6 \\
\hline $30 \leq 40$ & 23 & 27.1 \\
\hline Range & \multicolumn{2}{|c|}{$2.0-40.0$} \\
\hline Mean \pm SD & \multicolumn{2}{|c|}{$23.2 \pm 9.6$} \\
\hline \multicolumn{3}{|l|}{ Attending Courses in Management } \\
\hline No & 65 & 76.5 \\
\hline Yes & 20 & 23.5 \\
\hline
\end{tabular}


Table (2): Factors affecting decision making as perceived by the nurse managers in the public hospitals $(\mathrm{n}=85)$.

\begin{tabular}{|c|c|c|c|c|}
\hline \multirow{3}{*}{ Factors affecting decision-making } & \multicolumn{2}{|c|}{ Influencing } & \multicolumn{2}{|c|}{ Nurse managers' scores } \\
\hline & & & \multirow{2}{*}{ Min-Max } & \multirow{2}{*}{ Mean \pm SD } \\
\hline & No. & $\%$ & & \\
\hline Structural factors & 36 & 42.4 & $48.0-100.0$ & $78.6 \pm 11.7$ \\
\hline Process factors & 37 & 43.5 & $51.5-100.0$ & $79.4 \pm 13.0$ \\
\hline Outcome factors & 32 & 37.6 & $33.3-100.0$ & $74.3 \pm 18.5$ \\
\hline Individual factors & 29 & 34.1 & $33.3-100.0$ & $72.9 \pm 13.7$ \\
\hline Total factors & 36 & 42.4 & $57.7-92.5$ & $76.7 \pm 10.0$ \\
\hline
\end{tabular}

Table (3): Mean and standard deviation of the nurse managers' scores toward general decision- making styles (GDMS) in the public hospitals $(\mathrm{n}=85)$.

\begin{tabular}{|l|l|l|l||}
\hline \multirow{2}{*}{ General decision- making styles } & \multicolumn{3}{|c|}{ Nurse managers' scores } \\
\cline { 2 - 4 } & Minimum & Maximum & Mean \pm SD \\
\hline Rational style & 5 & 15 & $10.5 \pm 2.3$ \\
Intuitive style & 7 & 20 & $13.7 \pm 2.9$ \\
Dependent style & 6 & 17 & $12.5 \pm 2.6$ \\
Avoidant style & 9 & 24 & $18.2 \pm 3.7$ \\
Spontaneous style & 7 & 23 & $16.5 \pm 3.6$ \\
\hline
\end{tabular}


Table (4): General decision-making styles (GDMS) levels as perceived by the nurse managers in the public hospitals $(\mathrm{n}=85)$.

\begin{tabular}{||l|l|l|l|}
\hline GDMS & Levels & No. & $\%$ \\
\hline \multirow{3}{*}{ Rational style } & High & 0 & 0.0 \\
& Moderate & 6 & 7.1 \\
& Low & 79 & 92.9 \\
\hline \multirow{5}{*}{ Intuitive style } & High & 4 & 4.7 \\
& Moderate & 26 & 30.6 \\
& Low & 55 & 64.7 \\
\hline \multirow{5}{*}{ Avopendent style } & High & 0 & 0.0 \\
& Moderate & 30 & 35.3 \\
& Low & 55 & 64.7 \\
\hline \multirow{3}{*}{ Spontaneous style } & High & 53 & 62.4 \\
& Moderate & 15 & 17.6 \\
& Low & 17 & 20.0 \\
\hline & High & 28 & 32.9 \\
& Moderate & 36 & 42.4 \\
& Low & 21 & 24.7 \\
\hline
\end{tabular}

Table (5): Correlation matrix between general decision-making styles (GDMS) and factors affecting decision making among nurse managers in the public hospitals.

\begin{tabular}{|c|c|c|c|c|c|c|c|c|c|c|}
\hline \multirow{3}{*}{$\begin{array}{l}\text { Factors affecting } \\
\text { decision-making }\end{array}$} & \multicolumn{10}{|c|}{ GDMS } \\
\hline & \multicolumn{2}{|c|}{$\begin{array}{c}\text { Rational } \\
\text { style }\end{array}$} & \multicolumn{2}{|c|}{$\begin{array}{c}\text { Intuitive } \\
\text { style }\end{array}$} & \multicolumn{2}{|c|}{$\begin{array}{l}\text { Dependent } \\
\text { style }\end{array}$} & \multicolumn{2}{|c|}{$\begin{array}{c}\text { Avoidant } \\
\text { style }\end{array}$} & \multicolumn{2}{|c|}{$\begin{array}{c}\text { Spontaneous } \\
\text { style }\end{array}$} \\
\hline & $\mathbf{r}$ & $\mathbf{P}$ & $\mathbf{r}$ & $\mathbf{P}$ & $\mathbf{r}$ & $\mathbf{P}$ & $\mathbf{r}$ & $\mathbf{P}$ & $\mathbf{r}$ & $\mathbf{P}$ \\
\hline Structural factors & 0.203 & 0.062 & 0.032 & 0.771 & 0.251 & $0.021 *$ & 0.387 & $0.0001 *$ & 0.241 & $0.026 *$ \\
\hline Process factors & 0.364 & $0.001 *$ & -0.064 & 0.558 & 0.136 & 0.213 & 0.249 & $0.022 *$ & 0.021 & 0.846 \\
\hline Outcome factors & -0.122 & 0.268 & -0.094 & 0.392 & 0.117 & 0.286 & 0.128 & 0.244 & 0.058 & 0.601 \\
\hline Individual factors & -0.012 & 0.916 & 0.082 & 0.454 & 0.109 & 0.32 & 0.438 & 0.0001 * & 0.233 & $0.032 *$ \\
\hline Total factors & 0.173 & 0.113 & 0.034 & 0.758 & 0.225 & $0.038 *$ & 0.47 & 0.0001 * & 0.246 & $0.023 *$ \\
\hline
\end{tabular}




\section{DISCUSSION:}

Nowadays, a lot of professionals and scholars believe that the most important function of management is the task of decision making (Al-Tarawneh, 2012). Directors dedicate considerable endeavor to taking proper decisions in the organization by adopting various styles which are influenced by numerous factors (Yoder- Wise, 2014). Hence nurse supervisors and directors need a full comprehension of these factors that influence the process of making decision and could enhance and develop their choices (Hoffman, Donoghue, \& Duffield, 2004).

As yielded by the current study, the highest mean score of factors affecting decision making of nurse managers was for process factors. Most nurses were reported that the most important factors influencing their decision were related to communication, information sources and analysis. This may be attributed to the fact that they make decision based on the available information through effective communication with other personnel in the work setting. These results are in congruence with Soliman (2010) who noticed that the most substantial variable affecting the act of taking decisions were connected with the process factors, namely communication and the data analysis. These findings can be assured by study of Sanz (2007) which revealed that the act of making decisions is influenced by the task factors related with the nature of the decision, for example, the financial pressure, the data quantity and quality, and uncertainness associated with each option. In addition, Slosky, Stern, Burke, \& Siminoff (2014) assured that the nurses' participation in taking decisions is substantially affected by their communication with the doctors in the work setting. It appears that the work setting brings more effect on nurse supervisors; they devote more time to process of making decisions and always search for more data (Scherman, 2005).

Concerning structure factors, the study findings revealed that the nurse managers considered the factors related to time and work organizations and systems as clear organizational levels, clear organizational structure, and available financial resources and has system for incentives and guidelines were the most factors affecting decision making in workplace. In a similar vein, Bogner (1997) assured that making decision is influenced by time as a crucial element. In agreement with this result, Effken, Verran, Logue, \& Hsu (2010) detailed that the clear structure and organizational levels help the nursing supervisors more when taking decisions. Besides, this agrees with Dubrin 
(2006) who stated that the budget is an ideal means of management which gives much aid to directors when designing the expenses appropriately. In addition, the study result is parallel to Soliman(2010) who explained that the variables connected with the systems and the work organization are more impacting and spurring when nurse supervisors take decisions. Moreover, Hannah, Uhl-Bien, Avolio, \&Cavarretta(2009) detailed that hospitals are identified with a very official leveled administrations with an overwhelming dependence on scripted regulations and rules for making decisions and the clinical and directorial routine. From another point of view, the results of the present study illustrated that shortage of nurses' numbers especially the experienced ones is most structure hindering factor for mangers' decision making. This result proved the findings of Hajbaghery \& Salsali (2005); Shirey, McDaniel, Ebright, Fisher, \& Doebbeling (2010) who stated the nurse supervisors announced that the insufficient number of nurses was the biggest obstacle in work and affected adversely on their choices and decisions.

Results also indicated that the outcome factors influencing decision making were less reported by nurse managers in the present study, and the most prominent factor of them was related to nurse's satisfaction with the decisions and implement decisions without objections. This could be attributed to the fact that some of the studied hospitals respect personal judgment and enhance nurses' autonomy. This is the same viewpoint of Yoder- Wise (2014) who announced that the organizational morals board, the organizational strategy, and ethics like self-regard, self-governance and benevolence are examples of the elements that encourage and support the process of taking decision. Meanwhile, the least prominent factor of the outcome factors was related to praise from supervisors. The findings of the present study are in agreement with Effken, Verran, Logue, \& Hsu (2010) who claimed that the process of decision making can be influenced by the culture of the organization and the maximum supervisory assistance.

On other hand, the lowest mean score was found on the individual factors. In this respect, most nurse managers considered that the most important factors influencing decision making were related to value, traditions, personal philosophy, emotional disturbances and insufficient experience or background. This could be attributed to that the nurse's values, traditions, and psychological state have a dominant effect on 
decisions. This interpretation is supported by Arkes, et al., (1994); Al-Tarawneh (2012) who cleared up that ethics is the gift and has a capable impact on decisions. On a similar line, Cheric \& Gebrekidan (2009) reported that the factors that influence the process of taking decisions included philosophy, ethics, identity, judgment, knowledge, expertise and perception. In this regard, Killeen (2012) reported that there are some requirements to the decision making process such as the leader's psychological and physical state, ethics, attitudes, learning, expertise, interests and culture.

Meanwhile, results showed that lack of self-confidence and lack of courage, are the most individual hindering factors for mangers' decision making. This may be explained by that these two factors are inter-related, and the lack of personal courage may decrease the nurse managers' self-confidence, and consequently decrease their feeling of professional identity and autonomy, which affects decision making participation. This result is in agreement with Hagbaghery, Salsali, \& Ahmadi (2004); Payne \& Bettman(2004) who claimed that to be self-assured is a crucial element in the successful process of taking decisions. Also, Yoder-Wise (2007) claimed that specific personal traits like self-assurance and self-regard are factors that influence the leader's will to take the risk in taking a decision or overcoming a problem. At the same time, Bird \& Wallis (2002) assumed that the choice or the decision the nursing directors take may be impacted by how much self-confident they are.

When leaders try to apply different styles of decision-making, they are likely to incline to take up a prevailing style (Thunholm, 2004). In this respect, the present study clarified that most nurse managers had low rational, low intuitive, low dependent, and moderate spontaneous decision-making styles. Meanwhile, they had high avoidant style. Descriptively, as mentioned before results revealed that most managers reported that there are different factors affecting their decision, in which direct managers to follow certain decision styles in nursing work place. In this regard, Yoder- Wise (2014) affirmed that the nursing directors use more than one style to take a decision that is influenced by many elements. Likewise, Moghadam, Tehrani, \&Amin (2012) elaborated the existence of diverse factors that influence how directors and managers deal with the situations that must be handled through a decision. And the decision makers, who face complex and changing internal and external 
environments, should have various skills and abilities to make decisions in order to deal with these extreme situations. This usually requires managers to evaluate their current skills and develop more creative approaches.

The results previously mentioned showed that the low rational nurse managers had low intuitive style as well as high avoidant style. This might be due to that most nurse managers who participated in the study were head nurses with nursing diploma, and not attending courses in management and as a result they avoid taking decision. As indicated by Scott \& Bruce (1995) the avoidant style is portrayed by deferral and disavowal. These results proved the findings of Riaz \& Anis-Ul-Haque (2012) which stated that the individuals utilizing the rational way when taking decision don't stay away from making decisions. Additionally, Lamba \& Ozdasli (2015) noted that it is commonplace that the directors taught in fields related to administration are the most ones adopting the rational style when making decisions. Consequently, it is normal that expert directors are more rational when taking their decisions and this reduces the harm that may happen because of the unconstrained and intuitive decision making.

Additionally, the intuition style is more appropriate for managers on top position who have a high educational level and wide experience in their areas of expertise. This finding goes in the same line with Smith (2006) who claimed that instinct or intuition is more proper for the directors positionally topped in the association. This is the same view of Singh (2001) who pointed out that supervisors and directors in the positions below confront complicated issues that are routine-type in nature and specific that's why they depend on the customized way when taking decisions. Such problems and adjacent decisions don not require any spontaneity and speedy intuitive analysis which is made by strategic management. The strategic management may face uncertain problems involving non-programmed decisions. Additionally, Patton (2003); Harteis \& Gruber (2008) assured that the instinctive style of decision making depends on education, expertise and learning and inborn reaction.

As mentioned before, the highest percentage of nurse managers had low (rational, intuitive and dependent) decision-making styles. These results can be explained by several studies of Loo (2000); Baiocco, Laghi, \& D'Alessio (2009); Lamba \& Ozdasli (2015) which stated that a higher detailed utilization of the rational style corresponded 
emphatically with the reliant. A possible explanation could be that an effort to seek advice from other people is a part of a rational process. These results are contradictory with Bavolar \& Orosova (2015) who stated that both the instinctive and rational styles of decision making are non-dependent.

Otherwise, a statistically significant relation was found between rational decision making style and process factor. This may be explained by the study result that showed majority of nurse managers reported that communication channels, means for analysis information, and opportunities for independent choices are the most common process factors affecting their decision making. This finding was supported by Hushmandi(2013); Nickakhlagh (2013) who illustrated that managers that use rational style making decisions depend on search and comprehensive analysis of all available information from the internal resources and external resources. These results are in accordance with Gunnarsson \& Stomberg (2009); Nunes, Rego, \&Nunes (2014) who asserted that the successful decision making is essentially based on analyzing the data. On other hand, Curseu \& Schruijer (2012) assured the existence of an immediate connection between rationality and individual differences in the decision making process. Meanwhile, Driver, Brousseau, \&Hunsaker (1993) clarified that the distinctions among people when they take decisions rely on two components: data utilize and focus (how many solutions targeted).

Furthermore, it is obvious from the study result that there was a statistically significant relation between factors affecting decision making with the three decision styles of dependent, avoidant and spontaneous. These results may be attributed to those nurse managers - who had these three styles - had different personalities and everyone has different gender, values, culture and life experiences, different knowledge levels and each person perceives and thinks differently. This is the same viewpoint of Marquis \& Huston (2014) who demonstrated that there are personal varieties in the process of taking decisions. In case that everyone gets the same data and utilizes the logical way in dealing with trouble, we can assume that very similar decisions are to be taken. Because everyone has different gender, values and life experiences and each person perceives and thinks differently, different decisions may be made if given the same set of circumstances. As mentioned before the results revealed that nurse managers' decisions are influenced by personal philosophy and 
emotional disturbances. This point of view is supported by Connor \& Becker (2003); Thunholm (2004) who stated that director' styles when taking decisions can be affected by diverse personal factors as emotional intelligence and self-direction manners. In conclusion, Ehrgott (2011) claimed that the distinction among directors when taking decisions relies upon the distinction in expertise, their logical capacity when framing observation and handling of data, extent of counseling, how much free to make a choice, accessibility of resources and the resonance and confidence between the team and the leader.

Moreover, the present study revealed that most nurse managers had low educational level and insufficient background in management. So this may be explained that nurse managers always possess these decision styles. In this respect, Hagbaghery, Salsali, \& Ahmadi (2004) affirmed that the nurse directors' education impacts their level, type and mode of sharing in taking decisions. On the same line, Al Shra'ah (2015) reported that expertise and learning procedure impact the style of making decisions for any director or in any association. Also, Schutzenhofer \& Musser (1994); Aarabi, Cheraghi, \& Ghyasvandian (2015) claimed that the academic qualification was believed as an effective factor for understanding the process of taking decisions. On the contrary, study results conducted by Slosky, Stern, Burke, \& Siminoff (2014) reported that the noteworthy involvement in taking decisions was not related with the higher academic qualification. Besides, Louri \& Salanterna (1998) stated that taking decisions was not impacted by learning and expertise.

On other hand, results proved no significant correlation between factors affecting decision-making and intuitive style. This is could be due to that the majority of nurse managers had enough time, clear organizational levels and structure, available job description, available financial resources, available information and had system for incentives and guidelines in their workplace. This finding rationalized by Judge \& Robbins (2006); David (2009) who claimed that managers who adopt the instinctive style of making decisions with time restriction and shortage of data. Similarly, Patton (2003) stated that associations are constantly supposed to take fast and precise decisions through a timeline base. It is considered that instinct is frequently utilized when time is constrained at all stages of taking a decision (Oblak \& Lipuscek, 2003). 
Generally, there are different factors affecting the ways in which decision makers concern with decision situations. Nurse Managers in public hospitals should look for effective personal characteristics that affect their responses to decision-making situations. And this can play an important role in public manager's orientation or disorientation to a special decision-making style.

\section{CONCLUSION:}

It was concluded, that less than half of nurse managers were influenced by the factors affecting decision making, and the highest mean score was for process factors, while the lowest mean score was for individual factors. Also, the highest mean percentage was for avoidant style, while the lowest mean percentage was for rational style. Finally, there was statistically significant correlation between factors affecting decision making and all general decision-making styles except intuitive style.

\section{RECOMMENDATIONS:}

In the view of this research, the following points are recommended:

\section{At the nursing students' level:}

- A reconsideration for the undergrad nursing educational program to accentuate reasonable preparation and use of taking decisions in nursing administration.

- Undergraduate nurses must be trained to make decisions in the real field in numerous clinics.

\section{At the novice directors' level:}

- They must go through a preparation course that is created and customized to the requirements they need to take over their new position.

- To enhance their experience, nurse directors and supervisors must be engaged in the process of taking decisions.

\section{At the old staff directors' level:}

- Training courses must be provided so that nurse directors can learn and practice making decisions. 
- Other means of professional development - such as workshops, seminars, and conferences - must be held and focus on making decisions so as to develop nurse directors' managerial competencies and skills.

- Continual checking and assessment must be conducted to nurse directors' styles of taking decisions and the quality of the decisions they take.

At the academic fact-finding level:

- Numerous field researches should be done to figure out the impact of the styles of taking decisions and the elements influencing decisions in the whole process of decision making.

\section{REFERNCES:}

Aarabi AI, Cheraghi MA, Ghyasvandian S. Modification of nursing education upgrading nurses' participation a thematic analysis. Glob J Health Science. (2015); 7(4):161-72. Doi:10.5539/gjhs.v7n4p161.

Al Shra'ah A E. The Impact of Decision Making Styles on Organizational Learning: An Empirical Study on the Public Manufacturing Companies in Jordan, International Journal of Business and Social Science. 2015; 6(4):55-62.

Al-Tarawneh HA. "The main factors beyond decision-making". Journal of Management Research. 2012; 4 (1): 1-23.

Arkes HL, Joyner CA, Pezzo MA, Nash J G, Siegel-Jacobs K, Stone E. The psychology of windfall gains. Organizational Behavior and Human Decision Processes. 1994; 59(1):331-347.

Baiocco R, Fiorenzo L. Decision Making Style among adolescents: Relationship with sensation seeking and locus of control. Journal of Adolescence. 2009; 32 (1): 963-967.

Basavanthappa B. Nursing administration . $2^{\text {nd }}$ ed. New Delhi, India: JPBMP; 2009. 
Bavolar J, Orosova O. Decision-making styles and their associations with decision-making competencies and mental health. Judgment and Decision Making.2015; 10(1):115-122.

Beschloss M. Presidential courage: brave leaders and how they changed America. New York, NY: Simon and Schuster; 2007.

Bird A, Wallis $\boldsymbol{M}$.Nursing knowledge and assessment skills in the management of patients receiving analgesia via epidural infusion. Journal of Advanced Nursing.2002; 40 (5):522-531.

Bogner M. Naturalistic decision making in health care. In: Naturalistic Decision Making. New Jersey: Lawrence Erlbaum Associates, Inc; 1997.

Charise A, Witteman H, WhyteS, Sutton E, Massimi M, Stephens L. Questioning Context: a set of interdisciplinary questions for investigating contextual factors affecting health decision-making. Health Expect. 2010; 14(2): 115-32.

Cheric A, Gebrekidan AB. Nursing leadership and management. Addis Ababa: Addis Ababa University; 2009.

Connor P E, Becker B W. Personal Value Systems and Decision-Making Styles of Public Managers. Public Personnel Management.2003; 32(1): 155-180.

Craig JV, Smyth RL. The evidence - Based Practice manual for nurses .Edinburgh: Churchill living stone; 2002.

Curseu P, Schruijer S. Decision styles and rationality: an analysis of the predictive validity of the general decision-making style inventory. Educational and Psychological Measurement. 2012; 72(6): 1053-1062.

David F R. Strategic management: concept and cases. $12^{\text {th }}$ ed. United States of America: Pearson Education, Inc; 2009. 
Dietrich C. Factors that influence decision making, Heuristics Used, and Decision

Outcomes. Online academic student pulse journal. 2010; 2(21):1-3. Available from: http://www.studentpulse .com/articles/180/decision-making-factors-that-influencedecision-making-heuristics-used-and-decision-outcomes.

Driver MJ, Brousseau KE, Hunsaker PL. The Dynamic Decision Maker. San Francisco, CA: Jossey-Bass Publishers; 1993.

Dubrin, A. Essentials of management ..$^{\text {th }}$ ed. USA: Thomson Delmar learning; 2006.

Dumler P M, Skinner J S. Primer for management . $2^{\text {nd }}$ ed. South-Western: College Pub; 2007.

Effken J A, Verran J A, Logue M D, Hsu Y C. 'Nurse Manager's decisions: fast and favoring remediation'. Journal of Nursing Administration. 2010; 40(4): 188195.

Ehrgott M. Trends in multiple criteria decision analysis. New York, NY: Springer; 2011.

Fox $T$ L, Spence $J W$. An examination of the decision styles of project managers: evidence of significant diversity. Information and Management.1999; 36 (6): 313320.

Gati I, Landman S, Dowidovitch S, Asulinperetz L, Gadassi R. From career decision-making styles to career decision-making profiles: A multi-dimensional approach. Journal of vocational behavior. 2010; 76(2): 277-291.

Greenberg J. Behavior in organizations .10 ${ }^{\text {th }}$ ed. Upper Saddle River, NJ: Prentice Hall; 2011.

Gunnarsson BM, Stomberg W. Factors influencing decision making among ambulance nurses in emergency care situations. International Emergency Nursing. 2009; 17(2): 83-89. 
Guo K L . A decision-making model for more effective Decision making by health care managers. American journal of nursing Decide. 2008; 27(2): 118-127. Available from:

http://journals.lww.com/healthcaremanagerjournal/Abstract/2008/04000/DECIDE_A _Decision_Making_Model_for_More_Effective.5.aspx. doi: 10.1097/01.HCM.0000285046.27290.90.

Hagbaghery MA, Salsali M, Ahmadi $F$. The factors facilitating and inhibiting effective clinical decision-making in nursing: a qualitative study. BMC Nursing research. $2004 ; 3(2): 1-11$.

Hajbaghery MA, Salsali M. A model for empowerment of nursing in Iran. BMC Health Service research. 2005; 5 (1): 24.

Hannah ST, Uhl-Bien M, Avolio BJ, Cavarretta FL. A framework for examining leadership in extreme contexts. The Leadership Quarterly .2009; 20(6): 897-919.

Harteis C, Gruber H. Intuition and professional competence: intuitive versus rational forecasting of the stock market. Vocations and Learning. 2008. 1(1): 7185.Available from http://link.springer.com/article/10.1007/s12186-007-9000-z. Doi: 10.1007/s12186-007-9000-z.

Hoffman K, Donoghue J, Duffield C. Decision-making in clinical nursing: Investigating contributing factors. Journal of Advanced Nursing. 2004; 45(1): 5362.

Huber D. Leadership and nursing care management. $5^{\text {th }}$ ed. London: W.B. Saunders co; 2014.

Hushmandi $R$. The relationship between the administrative decision making styles and organizational health in government agencies kazeroun city. Master thesis. The free University. Science and research unit Boyer Ahmad; 2013. 
Judge T, Robbins SP. organizational Behavior. $5^{\text {th }}$ ed. Pearson: Prentice Hall; 2006.

Killeen J. Dementia; making decisions. Scotland: Alzheimer's society, Nuffield foundation; 2012.

Lamba M, Ozdasli K .Influence of social Culture on Decision-Making Manner in Turkey: An Analysis with the Structural Equation Model. Anthropologist. 2015; 19(2):341-353.

Loo R. "A psychometric evaluation of the general decision-making style inventory", Personality and Individual Differences.2000; 29(5):895-905.

Louri S, Salanterna S. Decision-making models in different fields of nursing. Research in nursing and health .1998; 21(5): 43-52.

Lussier $R$ N. Management fundamentals: Concepts, Applications, and Skill Development.$^{\text {th }}$ ed. The United States of America South Western: CengageLearning; 2014.

Marquis B L, Huston C J. Leadership roles and management functions in nursing Theory and application. $7^{\text {th }}$ ed. China, Philadelphia: Lippincott Williams\& Wilkins; 2014.

Moghadam A H, Tehrani M, Amin F. Study of the Relationship Between Emotional Intelligence (EI) and Management Decision Making Styles, World Applied Sciences Journal .2012;12 (7): 1017-1025.

Nickakhlagh S. The relationship between the leadership team with organizational learning and teachers empowerment in secondary schools. Master thesis. The free University.The unit of Saveh; 2013. 
Nunes $S$ R, Rego G, Nunes $R$. The experience of an information system for nursing practice: the importance of nursing records in management of a care plan. Computer Information Nurse. 2014; 32(7):322-332.

Oblak L, Lipuscek I. Intuitive decision making in a model of integral decision making scheme. Lesarstva: Zbornik gozdarstva; 2003.181-196.

Patton J R. (Intuition in decisions. Management Decision. 2003; 41(10): 989-996.

Payne J W, Bettman J R. Walking with the scarecrow: The information-processing approach to decision making. Blackwell handbook of judgment and decision making. Malden, MA: Blackwell Publishing; 2004.

Riaz M N, Anis-Ul-Haque M. Leadership styles as predictors of decision-making styles. African Journal of Business Management. 2012; 6(15):5226-5233.

Sanz M L. Factors that affect decision making: gender and age difference. International journal of psychology and psychological therapy, Espana.2007; 7 (3): 381-391.

Scherman RO. Growing our future nurse leaders. Nursing Administration Quarterly. 2005; .29(2): 125-132.

Schermerhorn J R, Management . $8^{\text {th }}$ ed. United State of America: John Wiley and sons; 2005.

Schutzenhofer KK, Musser D B. Nurse Characteristics and professional autonomy. Image-The Journal of Nursing Scholarship. 1994; 26 (1):201-205.

Scott S G, Bruce R A. Decision-making style: The development and assessment of a new measure. Educational and Psychological Measurement. 1995; 55(5): 818-831. 
Available from: http://www.sjdm.org/dmidi/General_Decision_Making_Style.html. Doi: $10.1177 / 0013164495055005017$.

Shirey M, McDaniel A, Ebright P, Fisher M, Doebbeling B. Understanding Nurse Manager Stress and Work Complexity. The journal of nursing administration. 2010; 40(2):82-91.

Singh RN. Organizational behavior: Concepts, theory, and Practices; 2001.

Slosky L E, Stern M, Burke N L, Siminoff L A. Decision making in the PICU: An examination of factors influencing participation decisions in phase III randomized clinical trials. International Journal of Pediatrics.2014; 2014 (676023): 1-6. Available from: http://dx.doi.org/10.1155/2014/676023.

Smith KJ. Teaching Medical Decision Modeling: A Qualitative Description of Student Errors and Curriculum Responses. Med Decis Making.2006; 26(6): 583588, Available from:

http://journals.sagepub.com/doi/abs/10.1177/0272989X06295360 $\underline{\text { Doi: }}$ $\underline{10.1177 / 0272989 \times 06295360 .}$

Soliman S. A study to investigate the factors that affect decision making among nurse managers in different hospitals in Zagazig (unpublished master's thesis). Faculty of nursing, Zagazig University; 2010.

Thunholm P. "Decision-making style: Habit, style or both?". Personality and Individual Differences. 2004;36(4):931944.Availablefrom:https://www.researchgate.net/publication/223850 903 Decision-making_style_Habit_style_or_both Doi: $10.1016 / \mathrm{S} 0191-$ $\underline{8869(03) 00162-4 .}$ 
Yoder-Wise PS. Leading and Managing in nursing . $6^{\text {th }}$ ed. Elsevier Mosby. The United States of America; 2014.

Yoder-Wise PS. Leading and managing in nursing $4^{\text {th }}$ ed . Canada: Mosby; 2007.

Yuan H, Kunaviktikul W, Klunkin A, Williams B. The Application of ProblemBased Learning in Chinese Baccalaureate Nursing Education. Nursing Education Perspectives. 2009; 30 (4):250-252.

العوامل المؤثرة على اتخاذ القرار لاى مديرات التمريض وعلاقتها بأسلوب اتخاذهن القرار

$$
\begin{aligned}
& \text { د. هند عبدالله محمد ، هلى رضا أحمد سليمان } \\
& \text { مدرس أدراة التصريض/كلية التصريض/ جامعة بورسعيد، ادارة التصريض /كلية التصريض/ جامعة بورسعيد }
\end{aligned}
$$

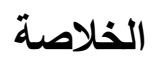

ان عمليه اتخاذ القرار تعد بمثابة قلب الادارة. حيث يتخذ المديرين العديد من القرارات كجزء من عملهم اليومي

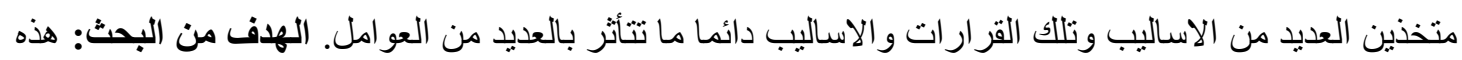
الدراسة أجريت لتحديد العوامل المؤثرة على اتخاذ القرار لاى مدير اتل التمريض و وعلاقتها بأسلوب اتخاذهم للقر ار ـ وقد تم استخدام در اسة وصفية تر ابطية .وقد شملت عينة الدر اسة (م) مديرة تمريض ممن يعملن داخل مستشفيات بورسعيد التابعة لوزارة الصحة. أدوات جمع البيانات: قد تم استخدام استمارتي استبيان لجمع لمعان

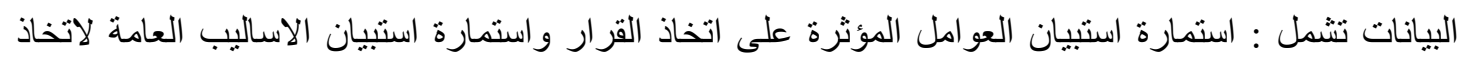
القرار. النتائج: كثفت نتائج الدراسة أن أقل من نصف (ء, بـ \%) مديرات التمريض نأثرن بالعوامل المؤثرة

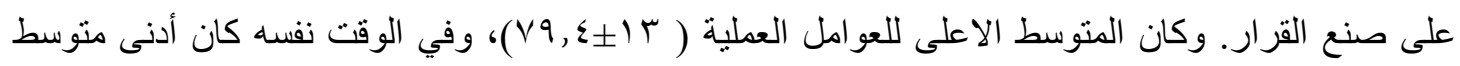
للعو امل الفردية (Y,Y



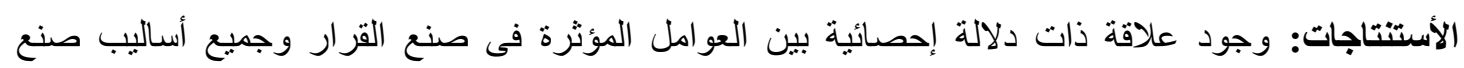

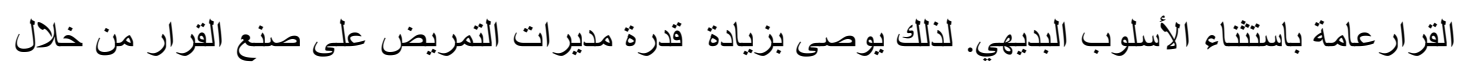

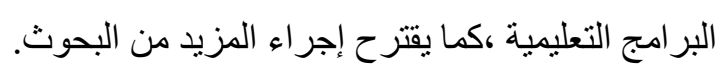

الكلمات المرشدة أساليب اتخاذ القرار، العوامل التي تؤثر على صنع القرار، مديرات التمريض. 